\title{
A systematic review of the clinical effectiveness of first-line chemotherapy for adult patients with locally advanced or metastatic non-small cell lung cancer
}

\author{
Gerlinde Pilkington, ${ }^{1}$ Angela Boland, ${ }^{1}$ Tamara Brown, ${ }^{2}$ James Oyee, ${ }^{3}$ Adrian Bagust, ${ }^{1}$ \\ Rumona Dickson ${ }^{1}$
}

- Additional material is published online only. To view please visit the journal online (http://dx.doi.org/10.1136/ thoraxjnl-2014-205914)

${ }^{1}$ Liverpool Reviews and Implementation Group (LRiG), University of Liverpool, Liverpool, UK

${ }^{2}$ Centre for Population Health Sciences, University of Edinburgh, Edinburgh, UK ${ }^{3}$ Covance Clinical Development Services, Maidenhead, UK

\section{Correspondence to} Dr Angela Boland, Liverpool Reviews and Implementation Group (LRiG), University of Liverpool, Room 2.08 Whelan Building, The Quadrangle, Brownlow Hill, Liverpool L69 3GB, UK angiela@liverpool.ac.uk

Received 17 July 2014 Revised 17 November 2014 Accepted 14 January 2015 Published Online First 6 February 2015

\section{ABSTRACT}

Our aim was to evaluate the clinical effectiveness of chemotherapy treatments currently licensed in Europe and recommended by the National Institute for Health and Care Excellence (NICE) for the first-line treatment of adult patients with locally advanced or metastatic nonsmall cell lung cancer (NSCLC). A systematic search of MEDLINE, EMBASE and the Cochrane Library for randomised controlled trials (RCTs) published from 2001 to 2010 was carried out. Relative treatment effects for overall survival (OS) and progression-free survival (PFS) were estimated using standard meta-analysis and mixed treatment comparison methodology. A total of 23 RCTs were included: 18 trials compared platinum-based chemotherapy, two compared pemetrexed and three compared gefitinib. There are no statistically significant differences in OS between any of the four thirdgeneration chemotherapy regimens. There is statistically significant evidence that pemetrexed+platinum increases OS compared with gemcitabine+platinum. There are no statistically significant differences in OS between gefitinib and docetaxel+platinum or between gefitinib and paclitaxel+platinum. There is a statistically significant improvement in PFS with gefitinib compared with docetaxel+platinum and gefitinib compared with paclitaxel+platinum. Due to reduced generic pricing, third-generation chemotherapy regimens (except vinorelbine) are still competitive options for most patients. This research provides a comprehensive evidence base, which clinicians and decision-makers can use when deciding on the optimal first-line chemotherapy treatment regimen for patients diagnosed with locally advanced or metastatic NSCLC.

\section{INTRODUCTION}

Lung cancer is the second most common cancer diagnosed in the UK after breast cancer, with over 40000 new cases being diagnosed in 2008. ${ }^{1}$ Non-small cell lung cancer (NSCLC) accounts for approximately $84 \%$ of all lung cancer cases ${ }^{2}$ and prognosis is poor; lung cancer is usually asymptomatic in the early stages and two-thirds of patients are diagnosed at a late stage (stages IIIB-IV) when curative treatment is not a viable option. ${ }^{1}$ Patients with a performance status (PS) of $0-1$ who are not eligible to receive potentially curative treatment such as surgery or radiotherapy, can receive chemotherapy, which could increase overall survival (OS) and progression-free survival (PFS), and improve health related quality of life (QoL). ${ }^{3}$
Our review focused on comparing all first-line treatments that are licensed in Europe and approved by the National Institute for Health and Care Excellence (NICE) for adult patients with locally advanced or metastatic NSCLC; currently, there is no available evidence base comparing all of these treatments. Recent clinical research ${ }^{4} 5$ related to histology and genetics has demonstrated important differences within the population of patients with NSCLC. Our review is unique in its focus on the efficacy of first-line treatments in the subpopulations of NSCLC patients, specifically patients with squamous disease, patients with non-squamous disease, and patients who are EGFR M+.

This review was commissioned by the National Institute for Health Research Health Technology Assessment (NIHR HTA) Programme. The review encompassed the clinical and cost effectiveness of first-line chemotherapy for adult patients with locally advanced or metastatic NSCLC; this paper summarises the findings of the clinical effectiveness review and provides a synopsis of the costeffectiveness analyses. ${ }^{6}$

\section{METHODS}

\section{Search strategy}

A comprehensive strategy was employed to search MEDLINE, EMBASE and the Cochrane Library for English language trials published from 2001 to August 2010. Details of the search strategy are presented in supplementary online table S1. To ensure completeness of the review, the American Society of Clinical Oncology (ASCO) database was searched to identify any relevant trials from details of conference abstracts. Bibliographic searches of included papers were also performed.

\section{Application of inclusion criteria}

Two reviewers independently screened all titles and abstracts; full-text copies of potentially relevant citations were obtained and were assessed for inclusion by two reviewers. Where necessary, a third reviewer was consulted for consensus.

Inclusion of studies was limited to randomised controlled trials (RCTs) comparing first-line chemotherapy treatments for adult patients with locally advanced or metastatic NSCLC; treatments had to be currently licensed for use in Europe and recommended by NICE. Trials were included if OS or PFS/time to treatment progression (TTP) were reported. Abstract only publications were excluded. 


\section{Data extraction and quality assessment}

Data on the following were extracted into an ACCESS database: trial design, patient characteristics, intervention details such as chemotherapy schedule and mode of administration, and outcome data including median OS, median PFS/TTP, overall response rate, 1- and 2-year survival, adverse events (AEs) and QoL data. All RCTs were assessed for methodological quality using criteria based on the Centre for Reviews and Dissemination guidance ${ }^{7}$ for undertaking reviews in healthcare. All data were extracted by one reviewer and independently checked for accuracy by a second reviewer; where necessary, consensus was achieved through consultation with a third reviewer.

\section{Statistical analysis}

To reflect current UK treatment pathways (see figure 1), analyses were undertaken and reported for three subpopulations of patients with NSCLC: patients with predominantly squamous disease, patients with predominantly non-squamous disease, and patients who were EGFR $\mathrm{M}+$. In the main, all analyses were conducted on the total population according to randomisation; however, subpopulation data were included in our analyses if used previously for international or national decision making.

We assume that the results of all studies that do not differentiate between subpopulations are equally applicable to patients with squamous disease and non-squamous disease. Before adopting this approach, we identified four third-generation studies $^{8-11}$ which reported multivariate statistical testing and included histology as a candidate explanatory variable. From our critique of these studies, we concluded that histology did not have a significant influence on outcomes for patients with squamous or non-squamous disease. In this review, all data applicable to the squamous population were derived from mixed population studies; however, none of the studies included in the review investigated the use of chemotherapy solely for patients with squamous disease.

In terms of direct evidence syntheses, standard meta-analysis (MA) was undertaken for each pair-wise treatment comparison using the 'metan' command within STATA V.9.2. ${ }^{12}$ For time-to-event outcomes (OS and PFS/TTP), the trial level estimate of $\log (\mathrm{HR})$ and its variance were extracted directly from trial publications if available. Additional data were requested whenever needed from the authors of trials in order to include as many relevant trials as possible in the MA. In the absence of direct estimates from published papers or requested from the authors, Kaplan-Meier (K-M) survival curves or log-rank statistics were used to estimate the required trial level log (HR) and its variance. ${ }^{13}{ }^{14} \mathrm{~A}$ random effects (frequentist) inverse variance weighted approach was used to pool estimates of $\log (\mathrm{HR})$ across trials.

An insufficient number of trials directly compared all chemotherapy treatment options and so multiple treatment comparison (MTC) methodology was undertaken in order to synthesise information on the relative efficacy of all included chemotherapy regimens. A Bayesian MTC framework was adopted to synthesise information on all chemotherapy technologies simultaneously using Markov chain Monte Carlo (MCMC) methods to estimate the posterior distributions for the outcomes of interest. WinBUGS V.1.4 statistical software ${ }^{15}$ was used for the MTC analysis by adapting codes from the Multi-Parameter Evidence Synthesis Research Group (MPES). ${ }^{16}$

OS and PFS/TTP results were expressed as HRs with 95\% CIs. Statistical heterogeneity was assessed by considering the $\chi^{2}$ test for heterogeneity with a $10 \%$ level of significance, and the I2 statistic with a value of $50 \%$ representing moderate heterogeneity. ${ }^{17} 18$

\section{RESULTS \\ Quantity and quality of included randomised controlled trials}

As shown in figure 2, electronic searches identified 5378 unique citations. Initial screening identified 240 potentially relevant references which were obtained as full-text articles and were assessed for eligibility for inclusion. After the exclusion of trials which did not compare the relevant interventions, 23 trials $^{4} \quad 5 \quad 8-11$ 19-35 comparing chemotherapy drugs currently licensed in Europe and recommended by NICE for the first-line treatment of patients with locally advanced or metastatic NSCLC, were included for evidence synthesis.

Quality assessment results are presented in supplementary online table S2. ${ }^{5}$ 8-11 19-35 All trials reported the number of patients randomised, however only six RCTs 8927283236 were assessed as adequately randomised with adequate concealment of allocation. All trials reported eligibility criteria; 20 trials reported detailed information about baseline comparability and three trials $^{202434}$ partially reported information about baseline comparability, but only five trials achieved baseline comparability. $^{10} 19222731$ Although the majority of trials reported

Figure 1 Treatment pathway.

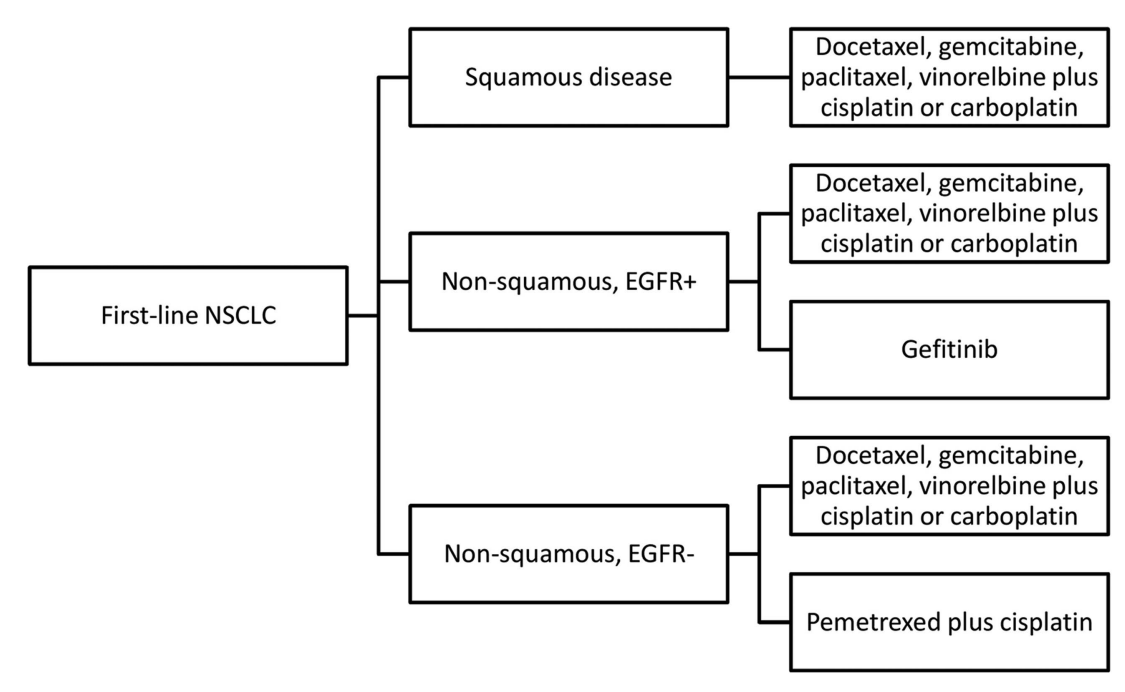


Figure 2 PRISMA flow diagram. ${ }^{41}$ CTX, chemotherapy; NICE, National Institute for Health and Care Excellence; RCT, randomised controlled trial.

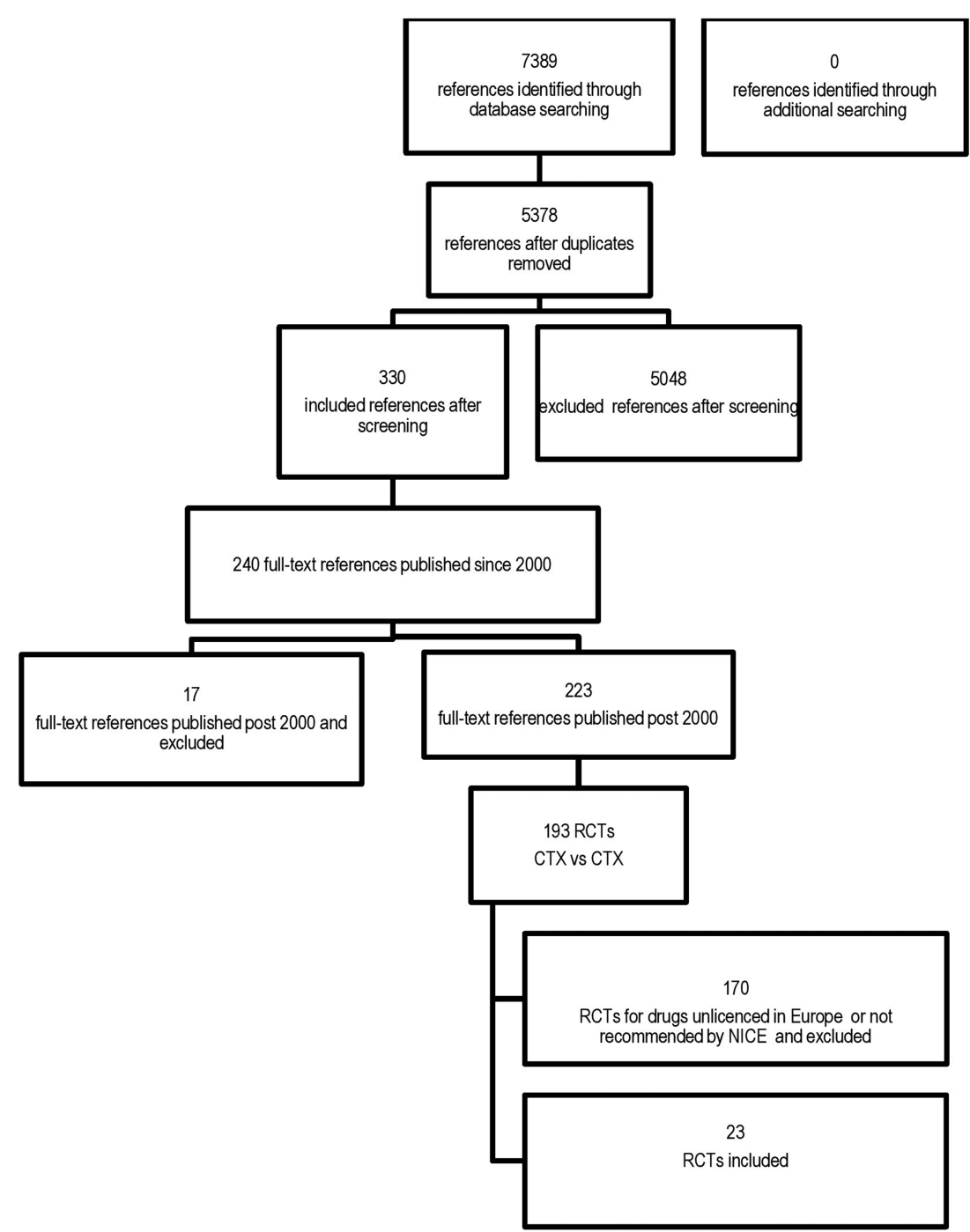

second-line chemotherapy, only one trial ${ }^{20}$ was designed to consider second-line therapy. Seven trials ${ }^{5} 10212^{29-32}$ were reported as 'open' and it was assumed that assessors, administrators and patients were not blinded to treatment except for one trial where the radiologist was stated to be blinded. ${ }^{31}$ Blinding of participants, investigators or outcome assessors was not reported in 16 studies. $48911 \quad 192022-28 \quad 33-35$ The outcomes of over $80 \%$ of patients were assessed in all studies and all studies reported reasons for dropout; 10 trials $^{4} 51019202224253033$ used an intention to treat approach to assess OS. Five of the trials appeared to report fewer outcomes than initially stated, thus indicating the possibility of selective reporting. 420242833

Overall, the quality of the included RCTs was poor-few trials fully reported methods and the definitions of the health outcomes used often differed between trials.

Trial characteristics

The 23 trials were published between 2001 and 2010. Of the 20 multicentre trials, six had multiple international centres. $^{458101130}$ The three single-centre trials were all located in Taiwan. ${ }^{19} 2235$ There are five phase II trials, ${ }^{19-23} 16$ phase III trials ${ }^{4} 5^{8-11} 24-33$ and two trials ${ }^{34} 35$ with phase undefined. Ten trials $45910202128-3033$ were funded solely by pharmaceutical companies, five trials ${ }^{11} 23 \quad 3132 \quad 34$ were funded by research grants, two trials ${ }^{824}$ were funded by both pharmaceutical companies and research grants, and funding was not stated in six trials. $^{19} 2225-2735$ Seventeen trials ${ }^{4} 5$ 8-11 $1920222426-29$ 32-34 were sufficiently powered to evaluate OS, four trials ${ }^{23} 253031$ were inadequately powered and the power of two trials ${ }^{21} 35$ was unclear. Median follow-up ranged from 11 to 40 months. Doses of chemotherapy drugs used varied, the median number of chemotherapy cycles ranged from 2.6 to 6 , and the route of administration was intravenous or oral. All trial characteristics details are set out in supplementary online table S3. ${ }^{4} 5$ 8-11 19-35

\section{Patient characteristics}

Overall, trial patients were generally younger, had better PS and less co-morbidity compared with patients typically treated in UK clinical practice. The majority of patients in the trials were male with adenocarcinoma stage IIIB or IV and of PS 1 . The percentage of males within each trial arm ranged from $56 \%$ to $84 \%$ for trials with platinum-based regimens incorporating thirdgeneration chemotherapy drugs. The number of patients randomised into individual trial arms ranged from 39 to 863 and median age ranged from 56 to 67 years.

Supplementary online table S4 presents all patient characteristics data. 4 5 8-11 $19-35$

\section{Categorisation of trials}

Reporting of trial outcomes has been categorised in the tables as squamous disease and EGFR $\mathrm{M}+$ patients. All trial outcomes follows: patients with squamous disease, patients with non- 
data are shown in supplementary online table S5. ${ }^{4} 5$ 8-11 $19-35$ Eighteen trials ${ }^{8-11} 19-283033-35$ in the NSCLC population with squamous disease are included; all 18 trials report outcomes for a mixed population (ie, trials include patients with squamous and non-squamous disease). Therefore, the results of these 18 trials are also applicable to the NSCLC population with nonsquamous disease. The outcomes for the NSCLC population with non-squamous disease are augmented by the addition of two trials ${ }^{4} 29$ which report specifically on subgroups with nonsquamous disease. In addition, outcomes for patients who are EGFR M+ are derived from three trials ${ }^{5} 3132 \quad 36$ and are categorised separately.

\section{NSCLC population with squamous disease}

Median OS was reported in all 18 trials and ranged from 6.2 to 15.4 months. ${ }^{19}{ }^{23}$ Median PFS/TTP was reported in all 18 trials and ranged from 3.0 to 8.4 months; ${ }^{19}{ }^{23}$ however, the definitions of PFS and TTP employed varied across trials.

One trial ${ }^{10}$ demonstrated significantly favourable survival estimates in a comparison between two regimens. In this study, ${ }^{10}$ patients in the docetaxel+cisplatin arm had a longer median OS compared to those in the vinorelbine+cisplatin arm. Two trials ${ }^{19} 34$ demonstrated differences in PFS/TTP between regimens; in one trial ${ }^{34}$ patients treated with gemcitabine + cisplatin had a significantly longer median PFS than those on paclitaxel+cisplatin, while in the other trial ${ }^{19}$ it was demonstrated that patients treated with vinorelbine + cisplatin had a significantly longer median PFS than patients treated with paclitaxel+cisplatin.

\section{NSCLC population with non-squamous disease}

In the two RCTs comparing pemetrexed, median OS rates ranged from 7.5 to 11.8 months. ${ }^{4}{ }^{29}$ One trial ${ }^{4}$ demonstrated a statistically significant difference in outcomes in patients with non-squamous disease who received pemetrexed+cisplatin compared with those receiving gemcitabine+cisplatin. Another trial $^{29}$ did not show any significant difference in OS when comparing pemetrexed+carboplatin with gemcitabine+carboplatin.

\section{NSCLC population with EGFR M+ status}

Three trials in the NSCLC population with EGFR M+ status were included, of which two ${ }^{31} 32$ included patients with EGFR $\mathrm{M}+$ status only, and the IPASS trial ${ }^{5} 36$ which selected specific patients in order to yield a relatively high proportion of participants with EGFR $\mathrm{M}+$ status. Where data are available, median OS ranged from 21.6 to 30.9 months. ${ }^{5} 3236$ There was no significant difference in OS when comparing gefitinib with paclitaxel+carboplatin in two trials ${ }^{5} 3136$ and there was no significant difference in OS between gefitinib and docetaxel+cisplatin in one trial. ${ }^{32}$ In contrast, the PFS results show a statistically significant benefit for patients receiving gefitinib compared with paclitaxel+carboplatin, and with docetaxel+cisplatin in all three trials. $^{5} 313236$

\section{Clinical effectiveness summary results}

Results summaries for all pair-wise comparisons between interventions from the direct MA and the MTC primary analyses for the three NSCLC populations are presented in supplementary online tables S2-S4. ${ }^{5}$ 8-11 19-35

\section{NSCLC population with squamous disease}

Eighteen trials ${ }^{8-11} \quad 19-28 \quad 3033-35$ were eligible for inclusion in the MA and MTC analyses in the population with squamous disease, with 7382 randomised patients and 6081 deaths (table 1). ${ }^{8-11}$ 19-28 $30 \quad 33-35$ The evidence related to outcomes for patients with squamous disease demonstrates that there are no statistically significant differences in OS between any of the four third-generation chemotherapy treatments. However, direct and indirect evidence suggest a potential advantage in terms of OS for gemcitabine+platinum (MA: HR 1.08, 95\% CI 0.98 to 1.20) and for docetaxel+platinum (MA: HR 0.89, 95\% CI 0.78 to 1.00 ; MTC-1: HR 0.92 , 95\% CI 0.81 to 1.03 ) compared with vinorelbine+ platinum, although this advantage is not statistically significant.

Only seven trials ${ }^{8} 192022232634$ were included in the PFS analysis and the majority of these trials used slightly different definitions of PFS. There was no evidence of any significant difference in PFS between the third-generation chemotherapy comparators.

A further seven trials ${ }^{9-11} 21253335$ reported results for the outcome TTP; there was no evidence of any statistically significant differences in TTP.

NSCLC population with non-squamous disease

Analyses for OS were based on 20 trials $^{48-11}$ 19-30 33-35 involving 9553 randomly assigned patients and 7608 deaths (table 2). ${ }^{4} \quad 8-11 \quad 19-30 \quad 33-35$ For patients with non-squamous disease, there is evidence that pemetrexed+platinum increases OS compared with gemcitabine + platinum (MA: HR 0.85, 95\% CI 0.73 to 1.00 ; MTC-1: HR 0.85 , 95\% CI 0.74 to 0.98 ). There is no evidence to conclude that there is any statistically significant difference between any of the other chemotherapy treatments in terms of increasing OS for patients with nonsquamous disease. Both the direct and indirect evidence suggest a potential advantage for gemcitabine+platinum compared with vinorelbine + platinum in terms of OS; however, this advantage is not statistically significant. Both the direct and indirect evidence suggest a potential advantage for docetaxel+platinum compared with vinorelbine + platinum in terms of OS; however, this advantage is borderline statistically significant (MA: HR 0.89 , $95 \%$ CI 0.78 to 1.00 ; MTC: HR 0.92 , 95\% CI 0.81 to 1.03). The MTC analysis shows a statistically significant difference between paclitaxel+platinum and docetaxel+platinum (HR 0.79 , 95\% CI 0.66 to 0.93 ), but the results of MA were not statistically significant.

\section{NSCLC population with EGFR M+ status}

Analysis for OS was based on the results of three trials 5313236 involving 663 randomly assigned patients and 199 deaths (table 3). ${ }^{5} 313236$ For patients with EGFR M+ status, there is no statistically significant difference in OS between gefitinib and paclitaxel+platinum or between gefitinib and docetaxel+platinum. There is evidence of a statistically significant improvement in PFS with gefitinib compared with docetaxel+platinum. While there is also evidence of a statistically significant improvement in PFS with gefitinib compared with paclitaxel+platinum, the significant heterogeneity between trials means the PFS results should be viewed with caution.

\section{Adverse events}

This review focused on AEs that were categorised in the published trial reports as being grade 3/4. Across trials, AEs were reported in a disparate fashion that was not amenable to comparison. Table 4 shows the 'top ten' AEs that occur in the greatest proportion of patients across all arms that used each chemotherapy treatment; AE data were extracted from each trial, grouping similar AEs and calculating the weighted average of the proportion of each $\mathrm{AE}$ according to each chemotherapy treatment administered. Certain AEs were grouped together; 
Table 1 MA and MTC results, NSCLC population with squamous disease

\begin{tabular}{|c|c|c|c|c|c|}
\hline Reference treatment vs comparator & $\begin{array}{l}\text { Number of data points } \\
\text { (trials with } \\
\text { head-to-head } \\
\text { comparison) }\end{array}$ & $\begin{array}{l}\text { Number of patients } \\
\text { in reference } \\
\text { treatment/ } \\
\text { comparator }\end{array}$ & $\begin{array}{l}\text { Number of events } \\
\text { (deaths) in reference } \\
\text { treatment/comparator }\end{array}$ & $\begin{array}{l}\text { MA } \\
\mathrm{HR}(95 \% \mathrm{Cl}) \\
\mathrm{N}=18\end{array}$ & $\begin{array}{l}\text { MTC } \\
\text { HR }(95 \% \mathrm{Cl}) \\
\mathrm{N}=18\end{array}$ \\
\hline \multicolumn{6}{|l|}{ Overall survival } \\
\hline GEM+PLAT vs VNB+PLAT $92125-2835$ & 8 & 1075/1077 & $842 / 860$ & $1.08(0.98$ to 1.20$)$ & 1.09 (0.99 to 1.19$)$ \\
\hline GEM+PLAT vs PAX+PLAT9 1123283334 & 6 & $1245 / 1344$ & $1053 / 1186$ & $1.03(0.94$ to 1.13$)$ & 1.05 (0.96 to 1.15$)$ \\
\hline GEM+PLAT vs DOC+PLAT ${ }^{34}$ & 1 & $301 / 304$ & $262 / 271$ & $1.06(0.89$ to 1.28$)$ & 1.00 (0.88 to 1.13$)$ \\
\hline VNB+PLAT vs PAX+PLAT 192428 & 4 & $625 / 630$ & $496 / 481$ & $0.98(0.83$ to 1.16$)$ & 0.96 (0.86 to 1.08$)$ \\
\hline VNB+PLAT vs DOC+PLAT 10202230 & 4 & $766 / 1175$ & $607 / 920$ & $0.89(0.78$ to 1.00$)$ & 0.92 (0.81 to 1.03$)$ \\
\hline $\mathrm{PAX}+\mathrm{PLAT}$ vs DOC+PLAT $\mathrm{T}^{34}$ & 1 & $602 / 304$ & $538 / 271$ & $0.98(0.76$ to 1.27$)$ & 0.95 (0.82 to 1.10$)$ \\
\hline \multicolumn{6}{|l|}{ Progression-free survival } \\
\hline GEM+PLAT vs VNB+PLAT ${ }^{8} 26$ & 2 & $269 / 269$ & $312^{*}$ & 1.09 (0.87 to 1.38$)$ & 1.06 (0.81 to 1.39$)$ \\
\hline GEM+PLAT vs PAX+PLAT ${ }^{23} 34$ & 2 & $350 / 656$ & $142 / 304 \dagger$ & $1.17(1.00$ to 1.36$)$ & 1.23 (0.94 to 1.62$)$ \\
\hline GEM+PLAT vs DOC+PLAT ${ }^{34}$ & 1 & $301 / 304$ & $105 / 114$ & $1.15(0.96$ to 1.37$)$ & 1.08 (0.79 to 1.45$)$ \\
\hline VNB+PLAT vs PAX+PLAT ${ }^{19}$ & 1 & $70 / 70$ & $7 / 14 t$ & 1.52 (1.06 to 2.17$)$ & $1.16(0.87$ to 1.61$)$ \\
\hline VNB+PLAT vs DOC+PLAT 2022 & 2 & $168 / 165$ & $92 / 86$ & $0.92(0.74$ to 1.16$)$ & 1.02 (0.78 to 1.36$)$ \\
\hline PAX+PLAT vs DOC+PLAT ${ }^{34}$ & 1 & $602 / 304$ & $130 / 263 \dagger$ & $0.97(0.75$ to 1.24$)$ & $0.88(0.62$ to 1.21$)$ \\
\hline \multicolumn{6}{|l|}{ Time to tumour progression } \\
\hline GEM+PLAT vs VNB+PLAT 9212535 & 4 & $433 / 436$ & $91 \dagger / 82 \dagger$ & $1.03(0.90$ to 1.18$)$ & 1.02 (0.83 to 1.25$)$ \\
\hline GEM+PLAT vs PAX+PLAT ${ }^{9} 1133$ & 3 & $744 / 742$ & $417 t / 423 t$ & $1.01(0.90$ to 1.13$)$ & 1.21 (0.73 to 1.99$)$ \\
\hline GEM+PLAT vs DOC+PLAT & 0 & No trial data & No trial data & No trial data & 0.98 (0.62 to 1.52$)$ \\
\hline VNB+PLAT vs PAX+PLAT ${ }^{9}$ & 1 & $203 / 204$ & $34 t / 37 t$ & $0.90(0.64$ to 1.28$) \ddagger$ & 0.99 (0.77 to 1.28$)$ \\
\hline VNB+PLAT vs DOC+PLAT ${ }^{10}$ & 1 & $404 / 406$ & $86+/ 88 \dagger$ & $0.96(0.70$ to 1.31$) \ddagger$ & 0.96 (0.65 to 1.43$)$ \\
\hline PAX+PLAT vs DOC+PLAT & 0 & No trial data & No trial data & No trial data & 0.98 (0.6 to 1.55$)$ \\
\hline
\end{tabular}

*In one trial PFS events were reported for both arms.

tIncludes progressive disease (PD) only as PFS/TTP event (PD or death) not reported.

‡Direct evidence.

Bold text indicates statistically significant results.

DOC, docetaxel; GEM, gemcitabine; MA, meta-analysis; MTC, mixed treatment comparison; NSCLC, non-small cell lung cancer; PAX, paclitaxel; PLAT, platinum; VNB, vinorelbine.

Table 2 MA and MTC results, NSCLC population with non-squamous disease

\begin{tabular}{|c|c|c|c|c|c|}
\hline Reference treatment vs comparator & $\begin{array}{l}\text { Number of data points } \\
\text { (trials with head-to-head } \\
\text { comparison) }\end{array}$ & $\begin{array}{l}\text { Number of patients } \\
\text { in reference } \\
\text { treatment/ } \\
\text { comparator }\end{array}$ & $\begin{array}{l}\text { Number of deaths in } \\
\text { reference treatment/ } \\
\text { comparator }\end{array}$ & $\begin{array}{l}\text { MA } \\
\text { HR }(95 \% \mathrm{Cl}) \\
\mathrm{N}=20\end{array}$ & $\begin{array}{l}\text { MTC } \\
\text { HR }(95 \% \mathrm{Cl}) \\
\mathrm{N}=20\end{array}$ \\
\hline \multicolumn{6}{|l|}{ Overall survival } \\
\hline GEM+PLAT vs VNB+PLAT $9925-283521$ & 8 & 1075/1077 & $842 / 860$ & $1.08(0.98$ to 1.20$)$ & 1.08 (0.99 to 1.18$)$ \\
\hline GEM+PLAT vs PAX+PLAT ${ }^{9} 1123283334$ & 6 & $1245 / 1344$ & $1053 / 1186$ & $1.03(0.94$ to 1.13$)$ & $1.06(0.97$ to 1.16$)$ \\
\hline GEM+PLAT vs DOC+PLAT ${ }^{34}$ & 1 & $301 / 304$ & $262 / 271$ & 1.06 (0.89 to 1.28$)$ & 0.99 (0.87 to 1.13$)$ \\
\hline GEM+PLAT vs PEM+PLAT ${ }^{4} 29$ & 2 & $1084 / 1087$ & $755 / 772$ & $0.85(0.73$ to 1.00$)$ & 0.85 (0.74 to 0.98$)$ \\
\hline VNB+PLAT vs PAX+PLAT 192428 & 4 & $625 / 630$ & $496 / 481$ & $0.98(0.83$ to 1.16$)$ & 0.92 (0.68 to 1.24$)$ \\
\hline VNB+PLAT vs DOC+PLAT ${ }^{10} 202230$ & 4 & $766 / 1175$ & $607 / 920$ & 0.89 (0.78 to 1.00$)$ & $0.98(0.87$ to 1.09$)$ \\
\hline VNB+PLAT vs PEM+PLAT & 0 & No trial data & No trial data & No trial data & $0.92(0.82$ to 1.03$)$ \\
\hline $\mathrm{PAX}+\mathrm{PLAT}$ vs $\mathrm{DOC}+\mathrm{PLAT}^{34}$ & 1 & $602 / 304$ & $538 / 271$ & $0.98(0.76$ to 1.27$)$ & $0.79(0.66$ to 0.93$)$ \\
\hline PAX+PLAT vs PEM+PLAT & 0 & No trial data & No trial data & No trial data & 0.85 (0.63 to 1.16$)$ \\
\hline DOC+PLAT vs PEM+PLAT & 0 & No trial data & No trial data & No trial data & $0.94(0.81$ to 1.09$)$ \\
\hline \multicolumn{6}{|l|}{ Progression-free survival } \\
\hline GEM+PLAT vs VNB+PLAT ${ }^{8} 26$ & 2 & $269 / 269$ & $312^{*}$ & 1.09 (0.87 to 1.38$)$ & $1.06(0.78$ to 1.66$)$ \\
\hline GEM+PLAT vs PAX+PLAT ${ }^{23} 34$ & 2 & $350 / 651$ & $142 / 304 \dagger$ & $1.17(1.00$ to 1.36$)$ & $1.23(0.77$ to 1.65$)$ \\
\hline GEM+PLAT vs DOC+PLAT ${ }^{34}$ & 1 & $301 / 304$ & $105 / 114$ & 1.15 (0.96 to 1.37$)$ & $1.08(0.7$ to 1.61$)$ \\
\hline GEM+PLAT vs PEM+PLAT ${ }^{4}$ & 1 & $1084 / 1087$ & NR & 0.90 (0.79 to 1.02$)$ & 0.90 (0.53 to 1.52$)$ \\
\hline VNB+PLAT vs PAX+PLAT ${ }^{19}$ & 1 & $70 / 70$ & $7 / 14 \dagger$ & 1.52 (1.06 to 2.17$)$ & $1.16(0.6$ to 1.65$)$ \\
\hline VNB+PLAT vs DOC+PLAT 2022 & 2 & $168 / 165$ & $92 / 86$ & $0.92(0.74$ to 1.16$)$ & 1.02 (0.61 to 1.44$)$ \\
\hline VNB+PLAT vs PEM+PLAT & No trial data & No trial data & No trial data & No trial data & 0.85 (0.42 to 1.51$)$ \\
\hline PAX+PLAT vs DOC+PLAT ${ }^{34}$ & 1 & $602 / 304$ & $130 / 263 \dagger$ & 0.97 (0.75 to 1.24$)$ & 0.88 (0.59 to 1.52$)$ \\
\hline PAX+PLAT vs PEM+PLAT & No trial data & No trial data & No trial data & No trial data & $0.73(0.42$ to 1.53$)$ \\
\hline DOC+PLAT vs PEM+PLAT & No trial data & No trial data & No trial data & No trial data & 0.83 (0.43 to 1.65$)$ \\
\hline
\end{tabular}

${ }^{*}$ Number of events are for both arms.

tIncludes progressive disease (PD) only as PFS event (PD or death) not reported.

Bold text indicates statistically significant results.

DOC, docetaxel; GEM, gemcitabine; MA, meta-analysis; MTC, mixed treatment comparison; NSCLC, non-small cell lung cancer; PAX, paclitaxel; PFS, progression-free survival; PEM, pemetrexed; PLAT, platinum; VNB, vinorelbine. 
Table 3 MA and MTC results, NSCLC population with EGFR M+ status

\begin{tabular}{|c|c|c|c|}
\hline Reference treatment vs comparator & $\begin{array}{l}\text { Total deaths/patients } \\
\text { in both arms }\end{array}$ & $\begin{array}{l}\text { MA } \\
\mathrm{HR}(95 \% \mathrm{Cl}) \\
\mathrm{N}=3\end{array}$ & $\begin{array}{l}\text { MTC } \\
\mathrm{HR}(95 \% \mathrm{Cl}) \\
\mathrm{N}=3\end{array}$ \\
\hline \multicolumn{4}{|l|}{ Overall survival } \\
\hline PAX+PLAT vs GEF ${ }^{5} 3136$ & $199 * / 448$ & $0.94(0.74$ to 1.18$)$ & $0.94(0.67$ to 1.3$)$ \\
\hline DOC+PLAT vs $\mathrm{GEF}^{32}$ & $\mathrm{NR} / 172$ & $1.64(0.75$ to 3.58$) \dagger$ & $1.64(0.54$ to 4.96$)$ \\
\hline $\mathrm{PAX}+\mathrm{PLAT}$ vs $\mathrm{DOC}+\mathrm{PLAT}$ & No trial data & No trial data & $0.57(0.18$ to 1.81$)$ \\
\hline \multicolumn{4}{|l|}{ Progression-free survival } \\
\hline PAX+PLAT vs GEF F $^{5136}$ & NR/488 & $0.38(0.24$ to 0.60$)$ & $0.39(0.29$ to 0.52$)$ \\
\hline DOC+PLAT vs GEF ${ }^{32}$ & $\mathrm{NR} / 172$ & $0.49(0.33$ to 0.73$) \dagger$ & $0.49(0.28$ to 0.86$)$ \\
\hline PAX+PLAT vs DOC+PLAT & No trial data & No trial data & $0.79(0.42$ to 1.48$)$ \\
\hline
\end{tabular}

*Overall survival events not reported by EGFR M+.

tDirect evidence.

Bold text indicates statistically significant results.

DOC, docetaxel; GEF, gefitinib; MA, meta-analysis; MTC, mixed treatment comparison; NR, not reported; NSCLC, non-small cell lung cancer; PAX, paclitaxel; PLAT, platinum.

'anaemia haemoglobin' was categorised into 'anaemia'; 'neutrophils' to 'neutropenia'; and 'sensory neuropathy', 'motor neuropathy' and 'neurotoxic effects' were all grouped into 'neuropathy'. Table 4 serves only to compare the profile of AEs within each chemotherapy regimen and should not be used to compare toxicities across the different drug regimens. Data show that neutropenia is the 'top' AE associated with vinorelbine, paclitaxel and docetaxel; granulocytopenia is the 'top' AE associated with gemcitabine and pemetrexed. Neutropenia, leucopenia and granulocytopenia all describe a fall in white blood count and so incidence rates of these AEs are similar across all the chemotherapy drugs with the exception of gefitinib which appears to have a different toxicity profile; the 'top' AE for gefitinib is aminotransferase elevation.

\section{Quality of life}

Only 12 trials $^{5}$ 8-11 $1922 \quad 24$ 27-30 36 reported outcomes relating to QoL, with QoL being the primary outcome in two trials. ${ }^{8}{ }^{29}$ MA was not performed due to limited data and variability in the outcome assessment measures reported. The paucity of data available means no firm conclusions can be drawn from the trial evidence described in the studies. The included trials used a number of standardised measurement tools: the European Organization for Research and Treatment of Cancer (EORTC) Quality of Life Questionnaire (QLQ)-C30 37 and the lung cancer-specific module QLQ-LC13 ${ }^{38}$ were used in three trials, ${ }^{8} 927$ the Lung Cancer Symptom Scale (LCSS) ${ }^{39}$ in four trials, ${ }^{10} 192230$ and the Functional Assessment of Cancer Therapy (FACT-L) ${ }^{40}$ in three trials. ${ }^{5} 242836$

Eight $^{8} 19222427-30$ trials did not report any significant difference in QoL between treatment groups. Four trials ${ }^{5}$ 9-11 36 reported some significant differences between treatment groups for QoL; in one trial ${ }^{9}$ results after two cycles of chemotherapy favoured the paclitaxel+carboplatin arm, whereas results after four cycles favoured the vinorelbine + cisplatin arm.

\section{SYNOPSIS OF COST EFFECTIVENESS}

Background

This review aimed to assess the relative cost effectiveness of four platinum-based chemotherapy regimens for the treatment of

Table 4 Top 10 adverse events by chemotherapy regimen

\begin{tabular}{|c|c|c|c|c|c|}
\hline $\mathrm{DOC}+\mathrm{PLAT}$ & GEM+PLAT & PAX+PLAT & PEM+PLAT & VNB+PLAT & GEF \\
\hline $\begin{array}{l}\text { Neutropenia } \\
71.4 \%\end{array}$ & $\begin{array}{l}\text { Granulocytopenia } \\
48.8 \%\end{array}$ & $\begin{array}{l}\text { Neutropenia } \\
62.5 \%\end{array}$ & $\begin{array}{l}\text { Granulocytopenia } \\
37.9 \%\end{array}$ & $\begin{array}{l}\text { Neutropenia } \\
68.3 \%\end{array}$ & $\begin{array}{l}\text { Aminotransferase } \\
\text { elevation } \\
33.8 \%\end{array}$ \\
\hline $\begin{array}{l}\text { Leucopenia } \\
43.5 \%\end{array}$ & $\begin{array}{l}\text { Asthenia } \\
40.3 \%\end{array}$ & $\begin{array}{l}\text { Leucopenia } \\
31.9 \%\end{array}$ & $\begin{array}{l}\text { Blood transfusions } \\
26.9 \%\end{array}$ & $\begin{array}{l}\text { Leucopenia } \\
47.2 \%\end{array}$ & $\begin{array}{l}\text { Appetite loss } \\
5.3 \%\end{array}$ \\
\hline $\begin{array}{l}\text { Weakness } \\
16.0 \%\end{array}$ & $\begin{array}{l}\text { Neutropenia } \\
36.4 \%\end{array}$ & $\begin{array}{l}\text { Weakness } \\
14.5 \%\end{array}$ & $\begin{array}{l}\text { Infection } \\
16.4 \%\end{array}$ & $\begin{array}{l}\text { Oedema } \\
24.0 \%\end{array}$ & $\begin{array}{l}\text { Rash/acne } \\
3.3 \%\end{array}$ \\
\hline $\begin{array}{l}\text { Pneumonitis } \\
11.5 \%\end{array}$ & $\begin{array}{l}\text { Thrombocytopenia } \\
34.6 \%\end{array}$ & $\begin{array}{l}\text { Cancer pain } \\
13.2 \%\end{array}$ & $\begin{array}{l}\text { Neutropenia } \\
15.1 \%\end{array}$ & $\begin{array}{l}\text { Anaemia } \\
19.3 \%\end{array}$ & $\begin{array}{l}\text { Toxic deaths } \\
3.1 \%\end{array}$ \\
\hline $\begin{array}{l}\text { Anaemia } \\
11.2 \%\end{array}$ & $\begin{array}{l}\text { Anorexia } \\
27.0 \%\end{array}$ & $\begin{array}{l}\text { Nausea } \\
10.3 \%\end{array}$ & $\begin{array}{l}\text { Alopecia } \\
11.9 \%\end{array}$ & $\begin{array}{l}\text { Phlebitis } \\
15.7 \%\end{array}$ & $\begin{array}{l}\text { Diarrhoea } \\
3.1 \%\end{array}$ \\
\hline $\begin{array}{l}\text { Asthenia } \\
10.2 \%\end{array}$ & $\begin{array}{l}\text { Leucopenia } \\
20.1 \%\end{array}$ & $\begin{array}{l}\text { Anaemia } \\
10.0 \%\end{array}$ & $\begin{array}{l}\text { Leucopenia } \\
8.2 \%\end{array}$ & $\begin{array}{l}\text { Nausea/vomiting } \\
11.5 \%\end{array}$ & $\begin{array}{l}\text { Neutropenia } \\
2.8 \%\end{array}$ \\
\hline $\begin{array}{l}\text { Nausea } \\
9.9 \%\end{array}$ & $\begin{array}{l}\text { Transfusion } \\
18.5 \%\end{array}$ & $\begin{array}{l}\text { Lethargy } \\
9.4 \%\end{array}$ & $\begin{array}{l}\text { Thrombocytopenia } \\
8.1 \%\end{array}$ & $\begin{array}{l}\text { Vomiting } \\
10.3 \%\end{array}$ & $\begin{array}{l}\text { Pneumonitis } \\
2.6 \%\end{array}$ \\
\hline $\begin{array}{l}\text { Vomiting } \\
9.8 \%\end{array}$ & $\begin{array}{l}\text { Alopecia } \\
17.2 \%\end{array}$ & $\begin{array}{l}\text { Thrombocytopenia } \\
8.3 \%\end{array}$ & $\begin{array}{l}\text { Anaemia } \\
7.0 \%\end{array}$ & $\begin{array}{l}\text { Nausea } \\
9.9 \%\end{array}$ & $\begin{array}{l}\text { Fatigue } \\
2.5 \%\end{array}$ \\
\hline $\begin{array}{l}\text { Cancer pain } \\
8.4 \%\end{array}$ & $\begin{array}{l}\text { Weakness } \\
17.0 \%\end{array}$ & $\begin{array}{l}\text { Neuropathy } \\
7.9 \%\end{array}$ & $\begin{array}{l}\text { Fatigue } \\
6.7 \%\end{array}$ & $\begin{array}{l}\text { Asthenia } \\
9.4 \%\end{array}$ & $\begin{array}{l}\text { Infection } \\
1.8 \%\end{array}$ \\
\hline $\begin{array}{l}\text { Infection } \\
7.5 \%\end{array}$ & $\begin{array}{l}\text { Anaemia } \\
16.5 \%\end{array}$ & $\begin{array}{l}\text { Vomiting } \\
7.4 \%\end{array}$ & $\begin{array}{l}\text { Nausea } \\
6.2 \%\end{array}$ & $\begin{array}{l}\text { Pain } \\
8.3 \%\end{array}$ & $\begin{array}{l}\text { Anaemia } \\
1.6 \%\end{array}$ \\
\hline
\end{tabular}

DOC, docetaxel; GEF, gefitinib; GEM, gemcitabine; PAX, paclitaxel; PEM, pemetrexed; PLAT, platinum; VNB, vinorelbine. 
advanced or metastatic NSCLC (docetaxel, gemcitabine, paclitaxel or vinorelbine in combination with either cisplatin or carboplatin) and two additional treatments for specific subgroups of patients with NSCLC (pemetrexed in combination with cisplatin for patients with non-squamous disease and single agent gefitinib for patients who are EGFR $\mathrm{M}+$ ).

\section{Methods}

Health outcomes and costs were modelled in three populations (squamous disease, non-squamous disease and EGFR M+) from a UK perspective. Regimens indicated for treating patients in each population were compared in terms of life years, quality adjusted life years, and healthcare and personal social care costs. Data from published RCTs with 24 months of follow-up were combined to generate typical non-linear temporal trajectories for each treatment option for OS and PFS, which were mutually calibrated using HRs at 12 months from the MTC described above. A cohort simulation model was developed to project patient experience and costs weekly, for 10 years, assuming up to two lines of chemotherapy. Deterministic and probabilistic incremental cost-effectiveness ratios (ICERs) were obtained for each population, using published list drug prices (base case) and also average health service contract drug prices.

\section{Results}

NSCLC population with squamous disease

In the squamous disease population, vinorelbine (oral or intravenous) doublets were shown not to be cost effective in either price scenario due to relatively poor outcomes. Paclitaxel, gemcitabine and docetaxel all lie on the efficiency frontier, but ICERs comparing interventions with better outcomes to paclitaxel exceed levels considered to be cost effective in the UK. The choice of platinum compound changes from cisplatin (base case) to carboplatin when contract drug prices are used, indicating that when drug costs are reduced, the location (and therefore cost) of administration influences cost-effectiveness estimates.

\section{NSCLC population with non-squamous disease}

In the non-squamous population, pemetrexed+cisplatin was shown to be a valid comparator to standard treatments and provides strong evidence of improved OS. However, its much higher price leads to non-competitive cost-effectiveness results.

\section{NSCLC population with EGFR+ status}

Evidence was found that EGFR $\mathrm{M}+$ patients have a better prognosis than other NSCLC patients; this means that gefitinib could only be compared with two standard treatments through evidence from three small trials which recruited from this specific patient subgroup. As there is currently no evidence of OS advantage, at the current price paid by the UK NHS, gefitinib does not appear to be cost effective compared to docetaxel or paclitaxel doublets.

\section{Conclusions}

The advent of routine histological and genetic testing in lung cancer patients and the introduction of widespread low-priced generic versions of standard chemotherapy products have altered the nature of the decision problem, and placed new branded drugs (pemetrexed and gefitinib) at a clear economic disadvantage. With the exception of pemetrexed, the differences in outcomes between the available treatment options are modest and may not be sufficient to influence clinicians in their choice of medication. However, the consistently poor performance of vinorelbine therapy may be an exception.

\section{DISCUSSION}

\section{Summary of results}

This is the first comprehensive systematic review of all first-line chemotherapy treatments currently licensed for use in Europe and recommended by NICE for adult patients with locally advanced or metastatic NSCLC. This review highlights that research in this area is evolving rapidly with advances seen in relation to subgroups defined by histology and genetic factors within the NSCLC population. Our results show that treatment effects differ for different subpopulations of patients with NSCLC.

\section{Generalisability of results}

In earlier trials that assessed the clinical effectiveness of thirdgeneration chemotherapy drugs, there was very little analysis of outcomes by factors such as histology or genetic markers and patients with NSCLC were classed as a homogeneous patient population. However, it is now accepted that NSCLC patients can be divided into at least three subpopulations: patients with squamous disease, patients with non-squamous disease and EGFR M+ patients. Our comparisons of available drugs for different subpopulations of patients with NSCLC are therefore extremely timely and should prove useful for decision-makers.

The evidence relating to patients with EGFR M+ status is based on the results from three trials ${ }^{5} 313236$ conducted in East Asian countries. It is questionable whether the results of these trials are generalisable to UK clinical practice as evidence suggests that East Asian populations with NSCLC have a more favourable prognosis compared with non-East Asian populations. ${ }^{41}$ EGFR mutation rates are likely to differ between countries (in Europe and the UK estimated EGFR M+ rates are low compared to Asian countries), ${ }^{42}$ although the actual response to chemotherapy may not differ in patients with the same mutation status. Evidence from our review shows that patients who are EGFR $\mathrm{M}+$ have improved OS outcomes compared to all other patients. As yet there are no relevant UK-based trial data for patients with EGFR M+ status; this is not surprising as only a small proportion of UK patients participate in international RCTs. In trials where ethnicity is not a risk factor for disease, this is less of a problem when considering the generalisability of results.

Clinical effectiveness results relating to the elderly population with NSCLC may be under-represented by the findings of the review. The majority of trials have an upper age limit for entry, whereas in clinical practice a substantial proportion of patients are over 75 years of age. The majority of published trials focus on fitter populations with less co-morbidity than the average UK patient with NSCLC. In addition, single-agent regimens were excluded from the review as none of these are currently licensed for single-agent use. However, NICE clinical guidelines ${ }^{3}$ state that docetaxel, gemcitabine, paclitaxel and vinorelbine can be administered as single agents if patients are intolerant of a platinum-based regimen, and this may include a larger proportion of elderly patients.

\section{Strengths and limitations}

Due to the large volume of related literature in this field, pragmatic decisions were made about the inclusion criteria and the focus of the data analyses was restricted to trials published after 2000. No direct evidence was identified for six pair-wise comparisons of chemotherapy drugs, which was a limitation; however, a particular strength of this review is its use of indirect evidence from MTC analyses to compare relative treatment 
effects across all first-line chemotherapy regimens that are licensed in Europe and recommended by NICE for patients with NSCLC. The results of comparisons which demonstrate borderline statistically significant results should be treated with caution and used to indicate possible differences in chemotherapy treatments that should then be assessed by a formal trial (ie, viewed as research generating) and should not be used alone to justify changes in clinical practice.

This report was limited in its analyses of AEs mainly because trials varied in the way AEs were defined, measured and reported. Reporting of AEs in RCTs needs to be standardised and reported consistently to allow future comparisons. Further research is required regarding the clinical significance of any of the reported AEs, as well as their significance to patients in terms of QoL. In addition, the introduction of new treatments with differing $\mathrm{AE}$ profiles needs to be considered. $\mathrm{OS}$ is an important outcome in deciding which chemotherapy drug a patient should receive, but this must be considered alongside the possible AEs and the symptomatic benefits of therapy. A lack of reporting of QoL data is a feature of the great majority of trials assessing outcomes of treatment for patients with NSCLC, and is a major shortcoming of lung cancer research despite the relevance and importance of QoL to patients and clinicians.

Carboplatin and cisplatin were grouped together and considered as 'platinum' and treated as similarly effective for the purpose of analysis. This decision was made following discussions with clinicians and was, in part, based on NICE guidelines $^{3}$ which recommend that either carboplatin or cisplatin may be administered depending on the balance of toxicity, efficacy and convenience for patients. It is noted that the results of recent meta-analyses ${ }^{44} 45$ suggest that cisplatin delivers greater efficacy than carboplatin, and that subsequently use of cisplatin has increased; however, clinical advice from experts confirms that clinical practice in the UK is still split between the two drugs. The results of the BTOG2 trial ${ }^{46}$ will help to clarify the evidence regarding the relative efficacy of cisplatin and carboplatin in terms of survival, QoL and the costs associated with each drug and its delivery.

\section{Overall conclusions}

This review provides a comprehensive evidence base which clinicians and decision-makers can use when deciding on the choice of first-line chemotherapy for an individual patient diagnosed with locally advanced or metastatic NSCLC. This systematic review is unique to the field in that it directly considers and compares all six chemotherapy treatments currently licensed in Europe and approved by NICE for the first-line treatment of adult patients with NSCLC. The results of the review highlight that from a clinical perspective, when examining data from patients with NSCLC, it is often difficult to distinguish between approved treatments in relation to their clinical effectiveness and so the decision about which drug to use will be based on clinicians' judgement and experience. However, the results of the economic analysis that was carried out alongside this clinical review reveal a somewhat different picture. As many of the older treatments are now off patent, they are relatively less expensive compared to the newer (and, in most cases, no more effective) treatments; this means that their cost effectiveness is more easily demonstrated at lower willingness to pay thresholds.

This review highlights the fact that research in this area is now predominantly focussed on histological subpopulations of NSCLC as well as molecular profiling within the NSCLC population. Eighteen out of 23 included trials investigated the treatment of any patient with NSCLC; only recently have trials included and/or reported their results using subpopulations. Recruitment into NSCLC trials will continue to change dramatically over the coming years when further subpopulations are taken into consideration and targeted agents are introduced.

Acknowledgements We thank clinical advisors and peer reviewers: David Baldwin, Paul Beckett, Jeremy Braybrooke, Andrew Champion, Jesme Fox, John Green, Matthew Hatton, Noelle O'Rourke, Michael Peake and Robert Rintoul. We thank authors of the Health Technology Assessment report: Michaela Blundell, Yenal Dundar, Janette Greenhalgh, Monica Lai, Carlos Martin Saborido and Catrin Tudur-Smith. We thank study authors who supplied additional data: Yuh-Min Chen, JY Douillard, Bjørn Henning Grønberg, Akira Inoue and Pascal Thomas.

Contributors $T B, A B o l, R D$ and $A B a g$ drafted the study protocol. TB and GP performed the systematic review. JO performed the statistical analyses. All authors contributed to the interpretation of data. GP, TB and ABol drafted the paper and all authors contributed to editing of the paper.

Funding This paper is based on a report commissioned by the National Institute for Health Research Health Technology Assessment (NIHR HTA) Programme (project number HTA 09/126/01).

Competing interests None.

Provenance and peer review Not commissioned; externally peer reviewed.

\section{REFERENCES}

1 Cancer Research UK. CancerStats: Lung Cancer and Smoking-Key Facts. http:// info.cancerresearchuk.org/cancerstats/types/lung/

2 The Information Centre for Health and Social Care. National Lung Cancer Audit: Key findings about the quality of care for people with Lung Cancer in England and Wales. Report for the audit period 2006-2007. http://www.ic.nhs.uk/services/ national-clinical-audit-support-programme-ncasp/audit-reports/lung-cancer

3 National Institute for Health and Clinical Excellence. The diagnosis and treatment of lung cancer CG 121, 2011. https://www.nice.org.uk/guidance/cg121

4 Scagliotti GV, Parikh P, Von Pawel J, et al. Phase III study comparing cisplatin plus gemcitabine with cisplatin plus pemetrexed in chemotherapy-naive patients with advanced-stage non-small-cell lung cancer. J Clin Oncol 2008;26:3543-51.

5 Mok TS, Wu Y-L, Thongprasert S, et al. Gefitinib or carboplatin-paclitaxel in pulmonary adenocarcinoma. N Engl J Med 2009;361:947-57.

6 Brown T, Pilkington G, Bagust A, et al. Clinical and cost effectiveness of first-line chemotherapy for adult patients with locally advanced or metastatic non-small cell lung cancer: a systematic review and economic evaluation. Health Technol Assess 2013;17:1-278.

7 Centre for Reviews and Dissemination. Centre for Reviews and Dissemination's guidance for undertaking reviews in health care, 2009. http://www.york.ac.uk/inst/ $\mathrm{crd} /$ pdf/Systematic_Reviews.pdf

8 Gridelli C, Gallo C, Shepherd FA, et al. Gemcitabine plus vinorelbine compared with cisplatin plus vinorelbine or cisplatin plus gemcitabine for advanced non-small-cell lung cancer: a phase III trial of the Italian GEMVIN Investigators and the National Cancer Institute of Canada Clinical Trials Group. J Clin Oncol 2003;21:3025-34.

9 Scagliotti GV, De Marinis F, Rinaldi M, et al. Phase III randomized trial comparing three platinum-based doublets in advanced non-small-cell lung cancer. J Clin Oncol 2002;20:4285-91.

10 Fossella F, Pereira JR, von Pawel J, et al. Randomized, multinational, phase III study of docetaxel plus platinum combinations versus vinorelbine plus cisplatin for advanced non-small-cell lung cancer: the TAX 326 study group. J Clin Oncol 2003;21:3016-24.

11 Smit EF, van Meerbeeck JPAM, Lianes $\mathrm{P}$, et al. Three-arm randomized study of two cisplatin-based regimens and paclitaxel plus gemcitabine in advanced non-small-cell lung cancer: a phase III trial of the European Organization for Research and Treatment of Cancer Lung Cancer Group-EORTC 08975. J Clin Oncol 2003;21:3909-17.

12 StataCorp. Stata Statistical Software: Release 9. College Station, TX: StataCorp LP, 2005.

13 Parmar MK, Torri V, Stewart L. Extracting summary statistics to perform meta-analyses of the published literature for survival endpoints. Stat Med 1998;17:2815-34.

14 Williamson P, Smith C, Hutton J, et al. Aggregate data meta-analysis with time-to-event outcomes. Stat Med 2002;21:3337-51.

15 Lunn DJ, Thomas A, Best N, et al. WinBUGS - a Bayesian modelling framework: concepts, structure, and extensibility. Stat Comput 2000;10:325-37.

16 Multi-parameter Evidence Synthesis Research Group. Formal methods for multiparameter evidence synthesis and their role in epidemiology and economic evaluation. http://www.bristol.ac.uk/cobm/research/mpes

17 Higgins J, Thompson S. Quantifying heterogeneity in a meta-analysis. Stat Med 2002;21:1539-58.

18 Higgins J, Thompson S, Deeks J, et al. Measuring inconsistency in meta-analyses. BMJ 2003;327:557-60. 
19 Chen YM, Perng RP, Shih JF, et al. A randomised phase II study of weekly paclitaxel or vinorelbine in combination with cisplatin against inoperable non-small-cell lung cancer previously untreated. Br J Cancer 2004;90:359-65.

20 Douillard JY, Gervais R, Dabouis G, et al. Sequential two-line strategy for stage IV non-small-cell lung cancer: docetaxel-cisplatin versus vinorelbine-cisplatin followed by cross-over to single-agent docetaxel or vinorelbine at progression: final results of a randomised phase II study. Ann Oncol 2005;16:81-9.

21 Thomas P, Robinet G, Gouva $\mathrm{S}$, et al. Randomized multicentric phase II study of carboplatin/gemcitabine and cisplatin/vinorelbine in advanced non-small cell lung cancer. GFPC 99-01 study (Groupe Francais de Pneumo-cancerologie). Lung Cancer 2006;51:105-14.

22 Chen YM, Perng RP, Shih JF, et al. A randomized phase II study of docetaxel or vinorelbine in combination with cisplatin against inoperable, chemo-naive non-small-cell lung cancer in Taiwan. Lung Cancer 2007;56:363-9.

23 Langer CJ, Li S, Schiller J, et al. Randomized phase II trial of paclitaxel plus carboplatin or gemcitabine plus cisplatin in Eastern Cooperative Oncology Group performance status 2 non-small-cell lung cancer patients: ECOG 1599. J Clin Oncol 2007;25:418-23.

24 Kelly K, Crowley J, Bunn PA Jr, et al. Randomized phase III trial of paclitaxel plus carboplatin versus vinorelbine plus cisplatin in the treatment of patients with advanced non-small-cell lung cancer: a Southwest Oncology Group trial. J Clin Oncol 2001;19:3210-18.

25 Gebbia V, Galetta D, Caruso M, et al. Gemcitabine and cisplatin versus vinorelbine and cisplatin versus ifosfamide+gemcitabine followed by vinorelbine and cisplatin versus vinorelbine and cisplatin followed by ifosfamide and gemcitabine in stage IIIB-IV non small cell lung carcinoma: a prospective randomized phase III trial of the Gruppo Oncologico Italia Meridionale. Lung Cancer 2003;39:179-89.

26 Martoni A, Marino A, Sperandi F, et al. Multicentre randomised phase III study comparing the same dose and schedule of cisplatin plus the same schedule of vinorelbine or gemcitabine in advanced non-small cell lung cancer. Eur J Cancer 2005;41:81-92.

27 Helbekkmo N, Sundstrom SH, Aasebo U, et al. Vinorelbine/carboplatin vs gemcitabine/carboplatin in advanced NSCLC shows similar efficacy, but different impact of toxicity. Br J Cancer 2007;97:283-9.

28 Ohe Y, Ohashi Y, Kubota K, et al. Randomized phase III study of cisplatin plus irinotecan versus carboplatin plus paclitaxel, cisplatin plus gemcitabine, and cisplatin plus vinorelbine for advanced non-small-cell lung cancer: four-arm cooperative study in Japan. Ann Oncol 2007;18:317-23.

29 Gronberg BH, Bremnes RM, Flotten 0, et al. Phase III study by the Norwegian lung cancer study group: pemetrexed plus carboplatin compared with gemcitabine plus carboplatin as first-line chemotherapy in advanced non-small-cell lung cancer. J Clin Oncol 2009;27:3217-24.

30 Tan EH, Rolski J, Grodzki T, et al. Global lung oncology branch trial 3 (GLOB3): final results of a randomised multinational phase III study alternating oral and i.v. vinorelbine plus cisplatin versus docetaxel plus cisplatin as first-line treatment of advanced non-small-cell lung cancer. Ann Oncol 2009;20:1249-56.

31 Maemondo M, Inoue A, Kobayashi K, et al. Gefitinib or chemotherapy for non-small-cell lung cancer with mutated EGFR. N Engl J Med 2010;362:2380-8.
32 Mitsudomi T, Morita S, Yatabe Y, et al. Gefitinib versus cisplatin plus docetaxel in patients with non-small-cell lung cancer harbouring mutations of the epidermal growth factor receptor (WJTOG3405): an open label, randomised phase 3 trial. Lancet Oncol 2010;11:121-8.

33 Treat JA, Gonin R, Socinski MA, et al. A randomized, phase III multicenter trial of gemcitabine in combination with carboplatin or paclitaxel versus paclitaxel plus carboplatin in patients with advanced or metastatic non-small-cell lung cancer. Ann Oncol 2010:21:540-7.

34 Schiller JH, Harrington D, Belani CP, et al. Comparison of four chemotherapy regimens for advanced non-small-cell lung cancer. N Engl J Med 2002;346:92-8.

35 Chang J, Tsao T, Yang C, et al. A randomized study of gemcitabine plus cisplatin and vinorelbine plus cisplatin in patients with advanced non-small-cell lung cancer. Chang Gung Med J 2008;31:559-66

36 Fukuoka M, Wu Y-L, Thongprasert S, et al. Biomarker analyses and final overall survival results from a phase III, randomized, open-label, first-line study of gefitinib versus carboplatin/paclitaxel in clinically selected patients with advanced nonsmall-cell lung cancer in Asia (IPASS). J Clin Oncol 2011;29:2866-74.

37 Aaronson N, Ahmedzai S, Bergman B. The European Organization for Research and Treatment of Cancer QLQ-C30: A quality-of-life instrument for use in international clinical trials in oncology. J Natl Cancer Inst 1993;85:365-76.

38 Bergman B, Aaronson N, Ahmedzai S. The EORTC QLQ-LC13: A modular supplement to the EORTC Core Quality of Life Questionnaire (QLQ-C30) for use in lung cancer clinical trials-EORTC Study Group on Quality of Life. Eur J Cancer 1994;30a:635-42.

39 Hollen PJ, Gralla RJ. Comparison of instruments for measuring quality of life in patients with lung cancer. Semin Oncol 1996;23(Suppl 5):31-40.

40 Cella D, Bonomi A, Lloyd S, et al. Reliability and validity of the Functional Assessment of Cancer Therapy-Lung (FACT-L) quality of life instrument. Lung Cancer 1995;12:199-220.

41 Ou S, Ziogas A, Zell J. Asian ethnicity is a favorable prognostic factor for overall survival in non-small cell lung cancer (NSCLC) and is independent of smoking status. J Thorac Oncol 2009:4:1083-93.

42 Rossell R, Moran T, Queralt C, et al. Screening for epidermal growth factor receptor mutations in lung cancer. N Engl J Med 2009;361:958-67.

43 Mitsudomi T, Yatabe Y. Mutations of the epidermal growth factor receptor gene and related genes as determinants of epidermal growth factor receptor tyrosine kinase inhibitors sensitivity in lung cancer. Cancer Sci 2007;98:1817.

44 Ardizzoni AL, Boni L, Tiseo M, et al. Cisplatin- versus carboplatin-based chemotherapy in first-line treatment of advanced non-small-cell lung cancer: an individual patient data meta-analysis. J Natl Cancer Inst 2007;99:847-57.

45 Jiang J, Liang $X$, Zhou $X$, et al. A meta-analysis of randomized controlled trials comparing carboplatin-based to cisplatin-based chemotherapy in advanced non-small cell lung cancer. Lung Cancer 2007;57:348-58.

46 Ferry D, Billingham L, Jarrett $H$, et al. British Thoracic Oncology Group Trial, BTOG2: randomised phase III clinical trial of gemcitabine $\left(1250 \mathrm{mg} / \mathrm{m}^{2}\right)$ combined with cisplatin $50 \mathrm{mg} / \mathrm{m}^{2}$ (GC50) versus cisplatin $80 \mathrm{mg} / \mathrm{m} 2$ (GC80) versus carboplatin AUC 6 (GCb6) in advanced NSCLC. National Cancer Research Institute, 7th NCRI Cancer Conference. Liverpool, 2011. 